Pensamiento Crítico N. ${ }^{\circ}$ 15, pp. 23-44

\title{
Importancia de la necesidad de la coerción mutua en la globalización o la descivilización progresiva
}

\author{
Mag. Jorge Barrera Herrera ${ }^{1}$
}

\section{RESUMEN}

La falta de inclusión dentro del actual modelo de crecimiento económico global adoptado por la mayoría de países del mundo, se evidencia por la creciente brecha que se está generando entre ricos y pobres, este modelo económico capitalistaliberal, que privilegia al mercado sobre todas las cosas, alienta la lucha por una mayor competencia y la realización de transacciones financieras especulativas de mayores rendimientos desalentando producir bienes o brindar servicios que son esenciales para la vida, donde el capitalismo se ha convertido en una plutocracia, es decir, en una oligarquía donde se concentran grandes cantidades de dinero que además ostentan el poder político mundial.

Según instituciones e investigadores de reconocido prestigio, indican que hay una desmedida ambición del $1 \%$ de la población mundial que no tiene reparos en condenar a la pobreza al $99 \%$ restante; indican que las 225 personas más ricas del mundo tienen un patrimonio que sumado superan el ingreso anual del $47 \%$ más

1 Profesor asociado y miembro investigador del Instituto de Investigaciones de la Facultad Ciencias Económicas de UNMSM. Estudios de Doctorado en Economía UNMSM. Magíster en Administración UESAN. Licenciado en Ciencias Marítimas Navales ESNA. 


\section{Pensamiento Crítico N. ${ }^{\circ}$}

pobre de la población, es decir cuentan con un ingreso equivalente a los ingresos de 2,500 millones de habitantes. Establecen que la máxima concentración de dinero se da en el capital financiero, específicamente en el sistema bancario global, el cual posee 60 veces más dinero que los propietarios del resto de negocios, fábricas, industrias de bienes y de otros tipos de servicios.

Sin embargo hay que reconocer también que según información confiable, la pobreza actualmente no llega al $13 \%$ de la población mundial, cuando hace tan solo 140 años esta llegaba al 85\%, lo cual podría estarnos indicando, que el aumento de las brechas mencionadas, es una preocupación exagerada. La liberalización económica ha permitido que nuestro país crezca a tasas líderes en forma sostenida en los últimos 10 años y que además, entre inicios de los $80 \mathrm{y}$ mediados de la primera década de este siglo, China ha logrado sacar a más de 500 millones de personas de la pobreza y que India, el segundo país más poblado del mundo, reduzca su porcentaje de pobreza a la mitad.

Otros indican que la causa de esta creciente brecha entre ricos y pobres es el desarrollo tecnológico el cual está ganando la carrera frente al capital humano y las habilidades organizacionales.

Esta situación de distanciamiento entre ricos y pobres es insostenible en el tiempo, porque generan problemas de gobernabilidad. Si consideramos que el poder es la capacidad de controlar recursos, en consecuencia son los ricos quienes concentran el poder político mundial, lo que ha motivado y seguirán produciendo protestas y movimientos como de los "indignados", "la primavera árabe" en el mundo, que quieren revertir estas grandes desigualdades $e$ inequidades.

La desigualdad en los ingresos y su consecuente creciente brecha entre ricos y pobres es motivo de preocupación y de diversos estudios de investigación para identificar un correcto diagnóstico y acertar en sus soluciones, dado que son muchas las variables monetarias y no monetarias cuya interrelación de efectos globales es muy difícil de analizar.

Es por este motivo que en este artículo se revisan algunos aspectos históricos considerados relevantes en el actual contexto global, como la importancia del Banco Central Norteamericano, la existencia del dinero fiduciario, la China de hoy y su roll en la antigua confrontación ideológica entre el MERCADO y LA PLANIFICACIÓN CENTRAL, la actual y progresiva desregulación bancaria del

país central, la receta de la doctrina económica del Consenso de Washington, los desbalances globales, la inflación y las burbujas financieras, que explicarían las 


\section{Jorge Barrera Herrera}

actuales consecuencias y situación del sistema monetario y financiero global en la que nos encontramos involucrados todos, planteándose algunas alternativas de solución, en sus efectos sobre la economía real y el bienestar social, como la necesidad de una mayor toma de conciencia colectiva global sobre la economía del bien común, a través de la necesidad de la coerción mutua a fin de lograr socializar adecuadamente los egoísmos, evitando una descivilización.

Palabras clave: mercado, planificación central, intervencionismo estatal, dictadura del proletariado, comunismo, capitalismo, plutocracia, descivilización, coerción mutua, globalización.

\section{ABSTRACT}

The lack of inclusion within the current global economic growth model adopted by most countries, evidenced by the growing gap that is being generated between rich and poor, the capitalist-liberal economic model that privileges the market over all things, encourages the struggle for greater competition and financial transactions to discourage speculation of higher yields produce goods or provide services that are essential for life, where capitalism has become a plutocracy, an oligarchy that is where they are concentrated large amounts of money also hold political power worldwide.

According institutions and researchers from prestigious indicate a boundless ambition than $1 \%$ of the world's population does not hesitate to condemn the remaining $99 \%$ poverty, indicate that the 225 richest people in the world have a combined equity than annual income of the poorest $47 \%$ of the population, or have an income equivalent to the income of 2.500 million. Provide that the maximum concentration of money is given in the financial capital, specifically in the global banking system, which has 60 times more money than the owners of other businesses, factories, industrial goods and other services.

However, we must also recognize that according to reliable information, poverty today is less than $13 \%$ of the world where 140 years ago only $85 \%$ is reached, which could for us to be indicating that the increase of the gaps mentioned is an exaggerated concern. Economic liberalization has allowed our country to grow at rates leading steadily in the last 10 years and also among the 80 early and middle of the first decade of this century, China has lifted over 500 million people of poverty and India, the second most populous country, reduce the poverty rate in half. 


\section{Pensamiento Crítico N. ${ }^{\circ}$}

Others indicate that the cause of this growing gap between rich and poor is the technological development which is winning the race against the human capital and organizational skills.

This distancing between rich and poor is unsustainable over time, because they generate problems of governance. Considering that power is the ability to control resources, therefore the rich who account for global political power, which has caused and will continue producing protests and movements as the "outraged", "Arab spring" in the world, who want to reverse these great inequalities and inequities.

Inequality in income and consequent growing gap between rich and poor is a concern and several research studies to identify the correct diagnosis and succeed in their solutions, since there are many non-monetary variables whose interrelationship of global effects is very difficult to analyze.

That is why in this article we review some historical aspects considered relevant in the current global context, the importance of the U.S. Central Bank, the existence of fiat money, the current progressive deregulation and central bank in the country, the recipe of the teaching Washington Consensus economic, global imbalances, inflation and asset bubbles, which would explain the consequences and present situation of global financial and monetary system in which we are engaged all, considering some alternative solutions in their effects on the economy real and social welfare, such as the need for greater collective awareness of the economics of global common good, through the necessity of mutual coercion to achieve selfinterest properly socialize, avoiding decivilization.

Keywords: market, central planning, state intervention, proletarian dictatorship, communism, capitalism, plutocracy, decivilization, mutual coercion, globalization.

\section{El banco Central Norteamericano (FED)}

El gobierno de Estados Unidos (USA) en 1913 creó el Banco Central de Estados Unidos (FED) y renunció a su derecho a controlar el suministro de moneda de la nación, ahora lo comparte disimuladamente con el poder financiero privado sin que sus ciudadanos y el mundo lo entiendan adecuadamente. 


\section{Jorge Barrera Herrera}

La FED es una corporación de propiedad y operación privada con fines de lucro, que opera a costa del bien público y erróneamente se cree que es el gobierno de los Estados Unidos el que la controla en su totalidad. $\left({ }^{1}\right)$

\section{Dinero fiduciario}

Es necesario tener en cuenta que, hoy dentro de la GLOBALIZACIÓN, el régimen monetario internacional cambió el 15 de agosto del año 1971, día en que el Presidente Nixon de los Estados Unidos en forma unilateral declaró nula la promesa de redimir pagar - oro por dólares en poder de Bancos Centrales del mundo, a razón de una onza de oro por cada $\$ 35$ dólares presentados para su cobro. (Compromiso asumido en Bretton Woods, 1945).

Al eliminar los Estados Unidos de Norte América el anclaje del dólar al patrón oro por el de deuda/crédito impaga creciente, alentó entre otros, principalmente al país central (Estados Unidos) a aumentar su endeudamiento, a devaluar su moneda y postergar necesidades de equilibrar sus presupuestos.

ACTUALMENTE, TODAS LAS MONEDAS NACIONALES SON MONEDAS FIDUCIARIAS O FIAT, INCLUYENDO AL DÓLAR NORTEAMERICANO, EL EURO Y TODAS LAS OTRAS MONEDAS DE RESERVA. $\left({ }^{2}\right)$ El tipo de dinero llamado fiduciario son las monedas y billetes que no basan su valor en la existencia de una contrapartida en oro, plata o cualquier otro metal noble o valores, ni en su valor intrínseco, sino simplemente en su declaración como dinero por el Estado y también en el crédito y la confianza (la fe en su futura aceptación) que inspira.

Dicho de otro modo, este sistema monetario desregulado está basado en una ilusión inflacionaria que por un lado, castiga la responsabilidad financiera y el ahorro, pero por otro, premia el dispendio y la deuda. El dólar es utilizado en el $85 \%$ de las transacciones internacionales y en esa moneda se contabiliza más de la mitad de la deuda internacional que circula en el mundo. Asimismo, más del $60 \%$ de las reservas internacionales de todos los bancos centrales está en dólares 


\section{Pensamiento Crítico N. ${ }^{\circ}$}

\section{La China de hoy y su roll en la antigua confrontación ideológica entre el mercado y la planificación central}

A inicios del siglo XX, la discusión ideológica sobre las mejores formas de organizar las sociedades se debatía entre dos grandes y confrontacionales tendencias, una era la del CAPITALISMO, en el que se privilegia al mercado como gran protagonista, basado en procesos de políticas democráticas, cuyos principales países promotores son los Estados Unidos de Norte América, Japón, países de occidente, y por otro lado el COMUNISMO, privilegiando la planificación central y destacando políticamente el partido único que detenta la dictadura del proletariado, en donde la URSS (en ese tiempo), China y algunos otros países más de Asia eran sus principales realizadores y promotores.

Es en este contexto que también a inicios del siglo XX y dentro del enfoque CAPITALISTA aparecen dos vertientes ideológicas económicas lideradas por dos grandes economistas de la época, el inglés John Maynard Keynes, que promovía un mayor intervencionismo estatal y el austriaco Friedrick Von Hayek, que promovía una economía sin intervención del estado en los mercados, llamada doctrina neoliberal, como un reformado modelo económico del propuesto anteriormente por los economista clásicos como Adam Smith y seguidores quienes también propugnaban un mercado libre, que este se autoregula y que era el mayoritariamente utilizado por los países capitalistas a principio del siglo XX.

Es como consecuencia de la gran recesión y crisis económica de los años 30 en los Estados Unidos, a las evidentes fallas del mercado y a las consecuencias de necesidades financieras de la Segunda Guerra Mundial (1944), que las propuestas del modelo económico de la demanda general de Keynes adquieren vigencia, dado que se ajustaban adecuadamente a las condiciones imperantes de la época que demandaban una mayor redistribución de la riqueza, disminuir el desempleo con presión inflacionaria controlada en los Estados Unidos. El Keynesianismo lo podía resolver, postulaba que el Estado, en el tema económico, debe ser más beligerante a través del gasto público; los mercados para atenuar sus naturales fallas deben ser adecuadamente regulados, utilizar políticas activas de gasto y déficit público, mayor énfasis en el corto plazo, una mayor relevancia al enfoque macroeconómico y de regulación de la demanda global. 


\section{Jorge Barrera Herrera}

El Keynesianismo en los países capitalistas, tuvo su época dorada hasta el año 1973, en que el modelo económico ya no se adecuaba a las nuevas condiciones de recesión e inflación de costos por la subida del precio del petróleo mundial creando una situación de estanflación, además por la ruptura del patrón oro - dólar, crecimiento excesivo del sector público que hacía ineficiente al estado y el cambio del sistema del tipo de cambio fijo al tipo de cambio flotante.

Es cuando el modelo neoliberal, adquiere importancia, en reemplazo del modelo económico keynesiano, dado que este modelo podía resolver los problemas de recesión e inflación, postulaba a una intervención mínima del estado, un mercado poco regulado para asegurar su gran flexibilidad y eficiencia, tener como primera prioridad un equilibrio presupuestal, énfasis en el largo plazo dando relevancia al enfoque microeconómico en políticas de competitividad. Dentro de este enfoque, aparece el Consenso de Washington, este modelo se utilizó con bastante éxito hasta la crisis financiera del 2008, de los préstamos hipotecarios sub-prime en los Estados Unidos.

La desregulación excesiva de los mercados financieros, que estaba en la base de esta última crisis, motivó que como solución nuevamente el modelo económico Keynesiano sea retomado por los capitalistas y con mayor énfasis, para a través del Estado (Bancos Centrales) poder dar fondos (diversificación cuantitativa) al sistema bancario hundido en la insolvencia e iliquidez.

Mientras las modelos económicos capitalistas se iban perfeccionando en sus aplicaciones globales, simultáneamente, a partir de la caída del muro de Berlín, 1989, la URSS comunista, se desintegra para formar un nuevo conglomerado de países Rusos, abandonando la ideología comunista para adoptar una estructura de gobierno capitalista con formas democráticas, terminando con la antigua disputa entre el mercado y la planificación central, es decir se determina que la organización económica de los mercados es más eficiente que la de la planificación central, imponiéndose entonces el liberalismo, los mercados y la democracia.

Es importante mencionar que en este proceso, y al tiempo de la transformación política Rusa, también la China poco a poco comenzó a privilegiar en sus políticas 


\section{Pensamiento Crítico N. ${ }^{\circ}$}

económicas al comercio internacional, utilizando un neo capitalismo que sin abandonar sus políticas de partido único, de dictadura del proletariado, tiende a privilegiar cada vez más la doctrina del mercado, construyendo un modelo económico híbrido de mercado y planificación central, algunos la llaman modelo pacífico y silencioso de expansión económica China, que está permitiendo financiar los grandes déficit públicos del país central los Estados Unidos, permitiendo mantener las tasa de interés norteamericana a la baja y un dólar igual que el yuan subvaluados, factores que hoy en día sintonizan con sus planes estratégicos de crecimiento económico Chino. Quién podía pensar que los Chinos, hoy, al mejor estilo capitalista, son los financistas de la primera potencia mundial.

La China ha liderado el crecimiento económico mundial en los últimos 30 años, alcanzando una tasa de crecimiento anual de $10 \%$ en este periodo, crecimiento basado en sus exportaciones e inversiones, llevándolas a niveles top en el mundo en relación a su producto (ver gráfico), sin embargo, y de acuerdo al último informa del Banco Mundial, el efecto de las grandes inversiones sobre el crecimiento de su producto bruto interno es cada vez menor (ver gráfico) explicado por la baja calidad de estas, debido a que el estado (planificación central) es quien las determina y además el control estatal de la banca es mayoritario (ver gráfico), razones que estarían aislando a los procedimientos del mercado Chino de la natural disciplina que obligan la competencia y eficiencia en los mercados de los países occidentales libres. La China ha demostrado, desde que inició su proceso de transformación, una gran capacidad de ir adecuando su original modelo económico expansionista a la coyuntura de los acontecimientos globales.

"El arte supremo de la guerra es someter al enemigo sin combatir", pensamiento Chino muy antiguo pero que de alguna manera refleja su estrategia económica expansionista, además es conocido otro dicho Chino, "lo importante no es de que color es el gato, sino que cace ratones". Es innegable que el nuevo roll que está asumiendo China en el actual contexto político-económico global y su proceso de legitimación del empresariado como una función social conveniente, constituye uno de los más importantes acontecimientos del siglo XXI y cuyo protagonismo y desarrollo ya está acondicionando el futuro histórico del presente siglo. 


\section{Jorge Barrera Herrera}
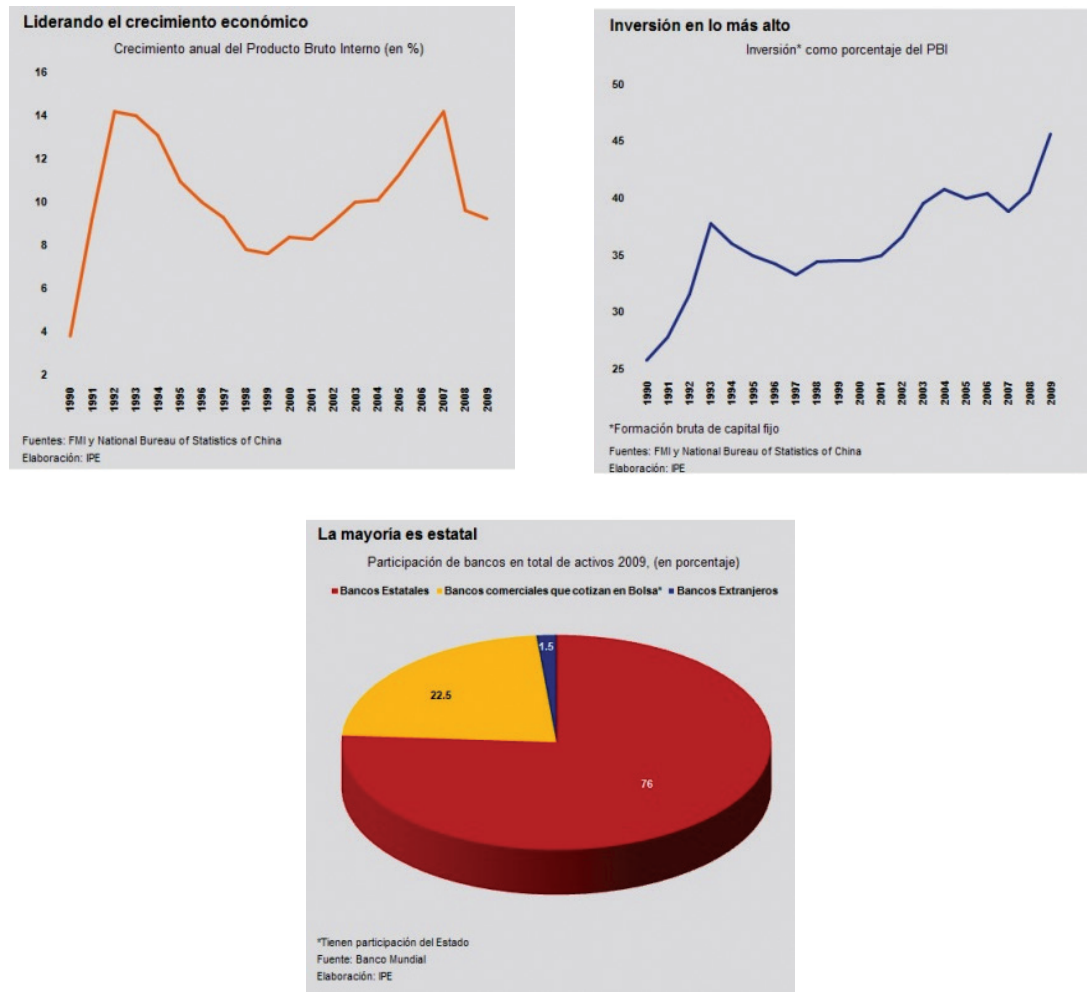

\section{Desregulación bancaria y financiera}

La Ley Bancaria del 16 de junio de 1933 o Ley Glass - Steagall es a la fecha la ley bancaria más revolucionaria que haya surtido efectos hasta el final del Milenio en los Estados Unidos.

Establecía entre lo más importante, la total separación de la actividad bancaria de la bursátil de manera de no arriesgar innecesariamente los ahorros del pueblo en inversiones especulativas y de alto riesgo y apoyó a los agricultores y a los bancos rurales, que sufrían fuertemente los embates de la Gran Depresión de 1929. Esta ley tuvo poderosos enemigos en el sector bancario a lo largo de toda su existencia. 


\section{Pensamiento Crítico N. I5}

En 1985, bajo la presidencia de Ronald Reagan, la Glass-Steagall recibió un golpe importante cuando el entonces jefe de Estado permitió que los bancos se convirtieran en asesores de inversión en la captación de recursos públicos. Reagan también facultó la puesta en marcha de instrumentos financieros no atados directamente a los bancos pero sí a sus fondos de inversión.

La presión del lobby bancario hizo que, en 1999, el expresidente norteamericano Bill Clinton y su secretario del Tesoro, Robert Rubin -actual asesor económico de Obama- derogaran, con la aprobación del Congreso, la Ley Glass-Steagall haciendo posible que todo aquello prohibido dejara de serlo.

\section{Consenso de Washington}

Después de la Gran Depresión de los años 30 en los Estados Unidos y de la Segunda Guerra Mundial (1944), se desarrolló en Europa y los Estados Unidos un modelo económico redistributivo del estado de bienestar que logró en las sociedades una mayor equidad en la distribución del ingreso de lo que había sido antes. La plutocracia norteamericana se consideraba que se le habían confiscado sus legítimas ventajas y por lo tanto querían cambiar el modelo económico redistributivo predominante.

Desde 1970, los ricos hicieron todo lo posible para evitar la regulación financiera alentando las transacciones especulativas en aras de la completitud de los mercados financieros (innovación financiera), utilizando todo lo necesario para lograr el apoyo ciudadano, como el marketing, los medios de comunicación, la gestión empresarial, el dinero para propagar la nueva doctrina NEOLIBERAL.

Parte de esta doctrina neoliberal, procedía del profesor universitario de Chicago Von Hayeck, mencionado en párrafos anteriores, que enseñaba a los "chicago boys" lo siguiente: la intervención del gobierno en la vida individual y social pondría a las nacio-

nes en el camino a la servidumbre. La libertad económica, el derecho a hacerse rico y a disponer de la riqueza sin interferencia externa, se colocaba en el mismo nivel que las libertades personales, religiosas y políticas establecidas en la constitución.

En 1989, el economista norteamericano John Williamson, estableció una escuela de pensamiento neoliberal, "Consenso de Washington", que fue un resumen de las 


\section{Jorge Barrera Herrera}

recomendaciones de los organismos financieros internacionales que en esos momentos tenían un gran protagonismo en la economía global, el Banco Mundial (BM), el Fondo Monetario Internacional (FMI), y del Tesoro de los Estados Unidos; para que los países lograsen alcanzar un crecimiento económico sostenido y que se basaban principalmente en: las privatizaciones, la liberalización y macroestabilidad especialmente controlando la inflación, en la gran fe en los mercados libres de restricciones sin intervención del Estado, el libre comercio internacional "la globalización", bienvenida a la inversión extranjera y el libre flujo internacional de capitales, asegurar que la mano de obra sea lo suficientemente flexible en busca de mayor competitividad.

\section{Desbalances globales}

Esto ha generado una nueva relación internacional dentro de la GLOBALIZACIÓN que alienta a los DESBALANCES GLOBALES, lo que algunos afirman están creando volatilidad e inestabilidad en el Sistema Monetario Internacional por sus imprevistas consecuencias en la confianza, en la sostenibilidad del sistema, en el crédito y la liquidez, lo que motiva drásticas reformas pendientes al sistema financiero. Este nuevo SISTEMA DUAL, algunos lo llaman el Bretton Woods II, de desbalances en donde los Estados Unidos, gastador, consumidor, sus déficits los cubre con emisión sin respaldo tradicional (patrón oro) y que los países emergente liderados por la China, Asia del Este, los países árabes petroleros y países emergentes, ahorradores, exportadores y con grandes reservas monetarias, financian estos déficits con sus superávits.

El sistema bancario y financiero en general, se cambió de un modelo "comprar para mantener" que incentivaba el ahorro y el trabajo, mas cerrada al comercio internacional, menos rentable y riesgoso, con tipos de cambio fijos, con bastante influencia del Fondo Monetario Internacional (FMI) y el Banco Mundial (BM), con presencia de dinero convertible; a un modelo de "generar para distribuir" más rentable y riesgoso que incentiva la deuda y los proceso fiduciarios (titulización) dentro de la reingeniería financiera devaluando el ingreso laboral, sistema monetario internacional desregulado, promoviendo la globalización y competitividad en casi todo excepto lo laboral por restricciones migratorias, con tipos de cambio flotante y políticas menos proteccionistas, con políticas monetarias/fiscales contracíclicas, con bastante presencia e intervención de los Bancos Centrales Nacionales, fondos de inversión, fondos soberanos y paraísos fiscales. 


\section{Pensamiento Crítico N. ${ }^{\circ}$}

\section{Los efectos de la política económica en una economía globalizada y viceversa.}

\section{Riesgo de inflación y las burbujas financieras}

El proceso de producción tiene lugar en un marco de tiempo, en donde los empresarios efectúan sus inversiones guiados por dos elementos claves: los precios y el tipo de interés, para asignar los recursos de la forma más eficiente posible en las distintas etapas del proceso.

La inyección fiduciaria o la expansión del crédito, por fuerza, distorsiona ambas señales, y conduce a los agentes económicos a efectuar malas inversiones.

En la medida en que se crea más dinero, en esa misma medida se devalúan las unidades monetarias ya existentes, enriqueciendo desmedidamente a quienes lo crean, y empobreciendo continuamente a quienes se encuentran al final de la cadena social.

Los efectos positivos de la inflación incluyen la posibilidad de los bancos centrales de los estados nacionales, de ajustar las tasas de interés nominal con el propósito de mitigar una recesión y de fomentar la inversión en proyectos de capitales no monetarios.

Las consecuencias de la inflación sumamente dañinas para las personas y para las sociedades, básicamente son tres:

1. Se corrompen las relaciones interpersonales.

2. Se somete a las poblaciones a una indetenida merma del poder adquisitivo, es decir, a una inflación permanente.

3. Se provoca la pérdida de autoestima y la descivilización generalizada.

La banca y las finanzas SIN CONTROL siempre van a la crisis, por una sencilla razón: porque prestan a largo plazo y deben los fondos que prestan, a corto plazo. Estos fondos son el dinero imaginario de los depositantes. En el momento en que dejan de crecer y tienen que comenzar a devolver dinero fiat físico a los depositantes, tienen que comenzar a cobrar sus créditos y todo se les descompone. La crisis se les ha venido encima. 


\section{Jorge Barrera Herrera}

Es decir, los proyectos tan sólo resultan rentables con tipos de interés artificialmente bajos. Además, se crean instrumentos financieros que alargan artificialmente la estructura productiva, aumenta el crédito laxo sin garantías, potenciando el fraccionamiento bancario, creando el dinero fiat imaginario, por lo que los agentes tienden a sobreinvertir en la producción de bienes de capital en detrimento de bienes de consumo, alentando las inversiones especulativas por la siempre existencia de mercados incompletos susceptibles de hacer arbitrajes creando, sin fundamentos, una falsa sobre valoración de activos (especialmente los inmobiliarios) propiciando una burbuja financiera.

El problema es que, tarde o temprano, esta situación se hace insostenible cuando aparece el "riesgo inflacionario". Es entonces cuando la autoridad política no puede mantener por más tiempo el interés bajo, saltando a la luz el volumen de malas inversiones efectuadas y reventando la burbuja financiera. Se produce una crisis de confianza, los créditos se paralizan y se seca la liquidez del sistema, generando descalces entre los ingresos y pagos, interrumpiendo el proceso. Como resultado, los efectos de la fase expansiva se invierten y los bancos centrales se ven obligados a subir las tasas de interés nominal para frenar la expansión monetaria y por ende la inflación.

La actual situación financiera se asemeja en mucho a la Gran Depresión de 1930 en los Estados Unidos, los años anteriores fueron precedidos por años de crecimiento explosivos de los títulos financieros de libre compra y venta en mercados globalizados, es decir se pretende que la riqueza sea el resultado no de la producción de bienes y servicios sino más bien de procesos de titulización o fiduciarios, que consisten en la creación de títulos que confieren derechos legales sobre los ingresos que generan los activos reales, actividad a la que se dirigen todos los esfuerzos de la banca por la alta rentabilidad que ofrecen; a la postre todo esto desencadena en la formación de una burbuja financiera, que por la falta de capacidad de la economía real de generar los recursos suficientes para honrar las obligaciones de pago contraídas, desencadena en una crisis que evidencia las consecuencias de operaciones especulativas y ausencia de valores de respaldo, convertibilidad o garantías.

Se debe tomar conciencia global de que los grandes intereses financieros, los plutócratas, siempre intentarán salvaguardar, hasta el final, el valor nominal de sus acreencias. No importa entonces que el costo de la crisis la carguen los deudores por entero y que en el proceso los niveles de producción y empleo bajen aún más y si esto 


\section{Pensamiento Crítico N. ${ }^{\circ}$}

no funciona entonces bienvenidos sean los fondos del tesoro público para el rescate y por tanto no habrá nunca propósito de enmienda, por lo que los mecanismos que activan la necesidad de la coerción mutua desaparecen.

Son pocos los castigos y sanciones a los ya identificados banqueros responsables de las grandes crisis financieras que finalmente repercuten globalmente en la economía real, también hoy, es por todos conocido el gran apoyo, asistencia y rescate, con dinero de los impuestos, que obtienen para su sostenibilidad de operaciones (riesgo sistémico), de los gobiernos, Bancos Centrales o Instituciones Rectoras Especiales, fomentando un riesgo moral, muy pragmático pero poco justificable y de consecuencias democráticas todavía por resolver.

\section{Consecuencias de la crisis en detalle: la descivilización}

La desconfianza y las turbulencias en los mercados, la agitación y el desánimo social, los enormes fraudes financieros y la inflación asfixiante endilgada por la excesiva ambición de ganancias de los agentes, de los gobiernos, del Sistema Bancario y el actual Sistema Monetario Internacional contra el pueblo de la Gran Aldea Global, todo ello tiene su origen en la falta de calidad del dinero, y en la consiguiente posibilidad de crear liquidez ficticia y crédito de la nada.

En la medida en que el dinero que usamos es ficticio, se provoca una ruptura cognoscitiva entre la realidad y la percepción de la misma, derivándose como efecto una confusión desquiciante.

La inflación, y la consiguiente devaluación monetaria provocan la degradación cultural y espiritual de la sociedad humana.

La manipulación del crédito y del dinero, por parte de las bancas centrales, equivale a trastocar la mente y el corazón de los individuos, siendo que el principal activo que uno posee es el fruto de su propio trabajo, el cual normalmente adquiere la forma de dinero.

Con el sistema de dinero fiat se comete el inmoral fraude de la inflación ( ${ }^{3}$ ) y el dinero pierde valor continuamente, los pueblos pierden su engranaje moral y se los conduce a la decadencia social o DESCIVILIZACIÓN permanente.Por la desaparición del valor intrínseco de las monedas, se da un desplome del ahorro, que es el fruto directo del trabajo humano. 


\section{Jorge Barrera Herrera}

\section{El Perú frente a la crisis}

Del Perú se espera que tenga un crecimiento económico de $5 \%$ para los próximos años por sus sólidos fundamentos y estabilidad de políticas macroeconómica, su liquidez externa continúa creciendo debido a los resultados de su cuenta corriente y a la acumulación de sus reservas internacionales netas (RIN), su deuda neta se ubicó en un $10 \%$ de su PBI en el 2011 con una creciente porción de deuda en soles a tasas fijas.

El modelo liberal actualmente en vigencia ha logrado que entre el 2003 y el 2011 el porcentaje de peruanos que pertenecen al sector socioeconómico más bajo se reduzca del $51 \%$ al $41 \%$. Detrás de esta cifra hay más de dos millones y medio de peruanos que han dejado la pobreza. Y en el período del 2002 al 2010 se ha conseguido que la mortalidad infantil en el país se reduzca casi a la mitad. En el índice Gini, que mide la desigualdad en la distribución del ingreso, el Perú cayó seis puntos entre el 2002 y el 2009, lo que significa que la distancia entre ricos y pobres se ha reducido y que los últimos han avanzado proporcionalmente más que los primeros.

Sin embargo, hay algunos factores que requieren algunas correcciones como el elevado nivel de dolarización financiera, con un $45 \%$ de los créditos y depósitos locales denominados en dólares, además los programas sociales implementados por el estado no muestran eficiencia en sus resultados,

En este proceso de la actual crisis, a todos los países no nos afecta por igual, sus consecuencias son en función de cuánto estén comprometidos nuestros sistemas financieros con la inflación y en los procesos fiduciarios que crean activos tóxicos. Felizmente en el Perú, nuestros procesos de titulización son transparentes, monitoreados

y con garantías prudenciales satisfactorias, no hay riesgos de falta de pagos o iliquidez a la vista, por ese lado el Perú no está comprometido, sin embargo no nos podemos librar de la inflación importada o exógena para lo cual el BCR y el MEF ya están tomando medidas preventivas, como estímulos fiscales y políticas monetarias contra cíclicas, para enfrentarla.

En esta coyuntura, el Perú debe promover mayormente su consumo interno e intentar cerrar sus carencias en infraestructura para ir cambiando su modelo exportador, dado que las materias primas constituyen más del $60 \%$ de sus exportaciones y de alguna 


\section{Pensamiento Crítico N. 15}

manera ir adecuándose a las necesidades de consumo de productos con más valor agregado. Tenemos que mejorar capacidades y lanzarnos a cerrar las brechas de la competitividad y de ese modo ser menos vulnerables y dependientes del exterior, como al parecer lo han entendido el Gobierno y el MEF.

\section{Conclusión: La necesidad de la coerción mutua}

Estamos atravesando momentos históricos de incertidumbre: las reglas del juego que existían en los años anteriores han dejado de funcionar, además no han surgido nuevas reglas que las sustituyan. En una situación de crisis personal, un agente puede tratar de desarrollar una estrategia racional para mejorar su situación, para salir de la crisis. Pero si su propio círculo de reconocimiento se está desmoronando, tendrá problemas para definir las preferencias sobre las que debe trazar su estrategia.

Las fuerzas y debilidades de las instituciones locales, nacionales y globales son importantes para definir y consolidar nuestra identidad individual, constituyen nuestro propio círculo de reconocimiento, nos ayudan a resolver dos problemas. Primero, complementan, o en ocasiones hasta sustituyen, a la sociedad en la formulación de preferencias sociales. Es decir, ayudan a decidir qué es lo que la sociedad quiere mediante mecanismos legítimos. Segundo, ayudan a superar los denominados problemas de acción colectiva.

Es decir, que para una persona en estas circunstancias puede ser prioritaria la adscripción a una identidad colectiva que defina sus preferencias, y sólo en un segundo momento buscará maximizar su utilidad en términos de esas preferencias compartidas.

La persona que necesita ante todo definir su propia identidad, auto identificarse a través de un colectivo, no es libre. Su carencia o crisis de identidad no le permite elegir, no tiene definidas las preferencias a partir de las cuales poder elegir, desarrollar una estrategia para alcanzar la satisfacción de un objetivo y no le permite tener una verdadera toma de conciencia sobre las consecuencias de su actos.

Por ejemplo, es digno de destacar que uno de los principales logros hasta ahora obtenidos por el entrenador de fútbol del equipo nacional, es haber conseguido una construcción de IDENTIDAD del colectivo de jugadores, de reconocidos méritos 


\section{Jorge Barrera Herrera}

profesionales individuales pero que antes de él sin evidencias de buenos resultados que mostrar. Con este trabajo de fortalecimiento e interiorización de valores, de toma de conciencia, se está construyendo una fuerte IDENTIDAD que permitirá potenciar el trabajo en equipo, mejorando la competitividad y productividad, generando sinergias que alientan la esperanza y hacen viable el poder alcanzar objetivos antes lejanos.

La definición de la propia identidad (y colectiva) se hace racionalmente prioritaria para los individuos, incluso adoptando formas contrarias a una idea sustancial de razón. Se puede ir más allá aún, para observar el gregarismo característico de algunos procesos de identificación colectiva. Esto podría estar explicando los recientes movimientos de masas tales como: la primavera árabe, y los movimientos de protesta de jóvenes "INDIGNADOS" en casi todos los países europeos y también en los Estados Unidos y países emergentes.

Las manifestaciones populares, como ola de protesta, están llegando hasta lugares donde el bienestar social es privilegiado. Un ensayo de lo que podría estar pasando en la aldea global por el desarrollo de la tecnología de comunicación de los medios sociales que posibilitan tener hoy un mundo bien enterado, es que:

1. Las autoridades elegidas por las democracias (políticos) son servidores de las grandes compañías (banqueros, grupos económicos) y no de las grandes mayorías. La nueva paradoja es que, en democracia, los que uno elige no son los que toman las decisiones más importantes.

2. Estados Unidos genera y colabora con constantes guerras cada vez menos comprendidas y justificadas.

3. Se están tomando medidas que han acabado con el estado de bienestar y protección del que gozaban los habitantes de esos países.

4. Nuestra aldea global (planeta) nos está dando señales de que ya no podemos seguir tratando sus recursos como si no hubiéramos llegado al estado evolutivo de entender lo que significa el término "renovable" y por tanto "sostenible". 


\section{Pensamiento Crítico N. 15}

Es necesario un nuevo pacto $\mathrm{u}$ ordenamiento político social, porque los que proponen los cambios son el $99 \%$ de la población y son personas que deben ser escuchadas, dado que el sistema democrático se rige por la expresión de la mayoría.

Los autómatas, los miedosos, los distraídos, los hipócritas, los interesados, los malos competidores, los desubicados, los rebeldes sin causa, los indignados, son personas sin identidad propia y por tanto sin identidad colectiva, lo que no les permite tener definidas sus preferencias a partir de las cuales poder elegir en el esfuerzo de alcanzar un objetivo predeterminado, este proceso trunco e ineficiente no le permite tomar verdadera conciencia de las consecuencias de sus actos, en especial para la colectividad, haciendo inviable la necesidad de la coerción mutua para ser más libres.

Cada vez que decimos a nuestros hijos "eso lo hacemos después" y ese después nunca llega, el niño que ve que toda su dedicación y afán de superación no son valorados, cada vez que nos comprometemos en algo y no cumplimos, cuando reclamamos por un servicio defectuoso y nos envían de un lado a otro sin solución, cuando no apreciamos, entendemos e interiorizamos el valor que tiene para el otro lo que uno hace y viceversa, es decir también ponernos en el lugar del otro, son algunos ejemplos en el día a día que muchas veces nosotros olvidamos que podemos cambiar y hacer la diferencia, comprender que nos toca a todos cultivar las virtudes de las que tanto se necesitan para reforzar los procesos de institucionalidad social, son acciones pequeñas que trascienden y que son valorados en el imaginario colectivo.

¿Cuál es nuestra realidad como peruanos en cuanto a la solides de algunos factores que refuerzan nuestra identidad? Por ejemplo, según el Latinobarómetro (octubre-2011), solo el $17 \%$ de los peruanos es consciente de sus obligaciones y deberes, el $38 \%$ de peruanos exige sus derechos, el $64 \%$ considera que los ricos son los que menos cumplen la ley.

¿Cómo reforzar la identidad personal y colectiva, en un mundo tan volátil y de tanta incertidumbre con proliferación de manipuladores, que no ayudan en el logro del bienestar social? Aunque parece irreal, solo con la meditación y creación como un proceso indivisible, dinámico y continuo, como un proceso sistémico más que individual, dándose uno tiempo para reforzar sus procesos creativos, tiempo para atender al yo interior, fomentando mejorar nuestra capacidad de imaginación y de atraer recuerdos 


\section{Jorge Barrera Herrera}

que son tuyos, alimentando tu recuerdo, poniéndose en el lugar de los demás. La formación de la identidad, no es un proceso que se circunscribe solo y dentro de las cabezas de las personas, sino a la interacción entre los pensamientos de una persona y un contexto sociocultural, es decir a la interacción de la cultura, la persona y un entorno de reconocimiento y validación, lo cual nos permitirá recuperar la conciencia, interiorizar, consolidar y ordenar nuestros pensamientos desde donde somos consientes y única vía para volver a nuestra memoria colectiva.

Este proceso de introspección que debe volverse voluntario y controlado, a veces con ayuda de profesionales, puede ser traumático y poco agradable, es muy sensible, además sus resultados en el mejoramiento de la estabilidad emocional no son inmediatos, ni fácilmente tangibles, ni de corto plazo, lo que no ayuda en su particular valoración y toma de conciencia de su importancia.

Si esto se realiza estarás en frecuencia de amor, es decir sin incoherencias entre tu interior y tu exterior, entre lo que sentimos dentro y lo reflejamos en el día a día en cada cosa que hagamos.

La clave está en lograr el equilibrio del yo como parte de un colectivo el mayor tiempo posible, entre el interior y el exterior del yo, entre nuestros pensamientos e ideas y sus materializaciones que son nuestros actos, entre la identificación de nuestras fuerzas $y$ debilidades interiores para interrelacionarme adecuadamente en el exterior con mis oportunidades y amenazas, proceso de amor que implica interrelación, obedecer al corazón, decisión, empatía con tu entorno, igualdad de voluntades, toma de conciencia y por tanto tener temor de DIOS, lo que nos permitirá tener conciencia de la necesidad de la coerción mutua.

Hay que despertar sin miedo, sin voluntad de colaborar con lo que no vibre a la par de nuestro corazón siempre justo y limpio (el hombre nace libre y la sociedad lo corrompe), entonces nosotros nos sentiremos seguros, claros en nuestras preferencias, seremos soberanos, libres y pondremos las reglas de juego.

Los individuos encerrados en la lógica de los recursos comunes (bienes públicos) son libres únicamente para traer la ruina universal; en las crisis financieras hay consenso que un largo período de inflación sostenida es causado cuando la emisión de dinero 


\section{Pensamiento Crítico N. ${ }^{\circ}$}

crece a mayor velocidad que la tasa de crecimiento económico o potencial (capacidad de la sociedad de crear bienes y servicios), pero es la codicia de los agentes y de las instituciones financieras rectoras, que con procedimientos de diversificación cuantitativa del dinero, inundan el mercado con sobre oferta de dinero fiat imaginario postergando soluciones definitivas, lo que nos lleva a las burbujas con explosión de crisis (para alcanzar el normal equilibrio y estabilidad) con sus consecuencias negativas sobre la economía real en la pérdida del valor adquisitivo del dinero y el bienestar social (pérdida de valor en función del tamaño de la brecha), esto es lo que nos obligará a ver la necesidad de la coerción mutua, lo que nos permitirá quedar libres para perseguir nuevas metas en el logro del bienestar social o por el contrario entrar en un proceso de descivilización global. Es pertinente recordar hoy y siempre lo que alguien dijo: "La libertad es el reconocimiento de la necesidad".

El reforzamiento de la identidad ciudadana no solo individual, nacional, hoy también global, solo se logrará con un mayor empoderamiento interno de los ciudadanos y en la toma de decisiones colectivas, una mayor inclusión de todos los ciudadanos en la distribución de la riqueza, en la mejor distribución y transparencia de la información en calidad y oportunidad, mayor universalización de las oportunidades, reconocimiento de las diferencias y de la meritocracia, valorar la importancia de los ingresos por el trabajo productivo como garantía del ahorro, fortalecimiento de una identidad individual y colectiva, lo que redundará en la existencia de mejores procesos dinámicos de institucionalización ciudadanos y estatales para la determinación de los límites de los derechos y obligaciones en las necesarias interrelaciones ciudadanas para el uso de los bienes comunes, definiendo en especial los derechos de propiedad y cumplimiento de los contratos.

Esto legitimará la función empresarial y la creación del capital, potenciando la identidad individual, colectiva y la toma de conciencia sobre la necesidad de coerción mutua para ser más libres y que las políticas en el uso de los bienes comunes (públicos), por los ciudadanos de la aldea global, tengan consecuencias renovables y sostenidas en el tiempo sobre el bienestar social.

Es evidente que todavía continúa la situación de crisis financiera y económica que atraviesa el mundo, a pesar que los medios de comunicación de los países desarrollados, tratan de suavizar sus internacionales consecuencias negativas; el mundo 


\section{Jorge Barrera Herrera}

está evidenciando la realización de una profunda reorganización del capital, utilizándose medidas de salvataje financieras a economías nacionales que expropian el patrimonio de los trabajadores, precarizando aún más el trabajo.

Esto nos revela que no se trata de una simple disfuncionalidad transitoria de los mecanismos y de la propiedad de los factores de producción del sistema y más bien nos cuestionan las afirmaciones de una asegurada prosperidad capitalista indefinida, que llegó a plantear después de la caída del muro de Berlín, el dogma "el fin de la historia".

Esta situación de incertidumbre, sobre las fuerzas y debilidades del capitalismo, está planteando y promoviendo iniciativas de modelos económicos alternativos, que busquen impulsar procesos democráticos y de integración, que incorporen conceptos tan venido a menos como: la solidaridad, cooperación, complementariedad e internacionalismo, que busquen ponerle límite a la especulación financiera y a la extracción descontrolada de los recursos naturales de los países pobres. Una iniciativa en este sentido podría ser el novedoso y expectante modelo económico híbrido de expansión Chino, que promete ser un protagonista importante en este esfuerzo.

\section{Notas de pie de página}

1. Leer a Thomas J. DiLorenzo es Investigador Asociado en The Independent Institute, profesor de economía en Loyola College en Maryland, y autor colaborador del libro, Taxing Choice: The Predatory Politics of Fiscal Discrimination.

2. El dinero fiat imaginario: Con el dinero fiduciario emitido por bancos nació otro tipo de dinero, que consiste en un saldo a favor de un cuenta-habiente en un banco. Al dejar de existir el dinero fiduciario, las cuentas bancarias de depositantes se volvieron cuentas en dinero fiat imaginario.

3. Leer Dornbusch, Rudiger. Macroeconomía. McGraw-Hill, 1998. 


\section{Pensamiento Crítico N. ${ }^{\circ}$}

\section{Bibliografía}

GAMBINA, Julio. (coord).(2010). La crisis capitalista y sus alternativas. Una mirada desde América Latina y el Caribe. Buenos Aires: CLACSO (2010).

CAPUTO LEIVA, Orlando. El dominio del capital sobre el trabajo y la naturaleza: nueva interpretación de la crisis actual.

PAINCEIRA PASCHOA, Juan Pablo e Marcelo, Días Carcanholo. "Crise Alimentar e Financeira: a lógica especulativa atual do capital fictício”. En Gambina, Julio. La crisis capitalista y sus alternativas.

FAIRLIE REINOSO, Alan. "Crisis internacional e integración regional". En Gambina, Julio. La crisis capitalista y sus alternativas. 